\title{
Editorial \\ Seismic imaging at the cross-roads: Active, passive, exploration and solid Earth
}

\author{
N. Rawlinson ${ }^{\mathrm{a}}$, R. Stephenson ${ }^{\mathrm{b}}$, R. Carbonell ${ }^{\mathrm{c}}$ \\ ${ }^{a}$ Department of Earth Sciences - Bullard Labs, University of Cambridge, Cambridge, \\ CB3 0EZ, UK Corresponding author: nrawlinson@abdn.ac.uk \\ ${ }^{b}$ School of Geosciences, University of Aberdeen, Aberdeen AB24 3UE, Scotland. \\ ${ }^{c}$ Institute of Earth Sciences-Jaurne Almera-CSIC, Barcelona, Spain
}

\section{Keywords:}

Seismic imaging, joint inversion, ambient noise, acquisition, continental crust, active source, passive source

\section{Introduction}

Science has grown from our need to understand the world around us. Seismology as a science is no different, with earthquakes and their destructive effect on society providing the motivation to understand the Earth's seismic wavefield. The question of when seismology as a science really began is an interesting one, but it is unlikely that there will ever be a universally agreedupon date, partly because of the incompleteness of the historical record, and partly because the definition of what constitutes science varies from person to person. For instance, one could regard 1889 as the true birth of seismology, because that is when the first distant earthquake was detected by an instrument; in this case Ernst von Rebeur-Paschwitz detected an earthquake in Japan using a pendulum in Potsdam, Germany (Ben-Menahem, 
1995). However, even the birth of instrumental seismology could be contested; the so-called Zhang Heng directional "seismoscope" (detects ground motion but not as a function of time) was invented in AD 132 (Rui and Yan-xiang, 2006), and is said to have detected a four-hundred mile distant earthquake which was not felt at the location of the instrument (Needham, 1959; Dewey and Byerly, 1969). Prior to instrumental seismology, observations of earthquakes were not uncommon; for instance, Aristotle provided a classification of earthquakes based on the nature of observed ground motion (Ben-Menahem, 1995).

While the origins of seismology as a science can be argued, there is little doubt that modern seismology, which combines the detection and recording of earthquake signals with theory, has its origins in the late 19th century with the development of early instruments designed to capture the oscillatory nature of ground motions associated with seismic waves. These often rudimentary seismometers were the progenitors of the more sophisticated instruments used by luminaries of the discipline including Mohorovičic to discover the Moho in 1909, Gutenberg to determine the depth to the coremantle boundary, and Lehmann to discover the inner core in 1936. While seismology can be regarded as a data-driven science, the development of theory necessary to explain the observations is obviously equally crucial. In the case of elastic wave theory, much of the developmental work was carried out in other fields prior to the advent of modern seismometers; this is also true of many other tools used by seismologists. This is not to say that the evolution of seismology involved little fundamental theoretical development; a well-known example is so-called elastic rebound theory (Stein and Wysession, 
2003), which described the gradual accumulation of elastic strain energy on either side of a fault prior to rupture. However, many of the tools used by modern seismologists to analyse and understand their data come from the mathematical and physical sciences, including time series analysis, solution of differential equations, inverse theory and many more.

Apart from the introduction of seismometers and recording systems, another revolution which profoundly influenced modern seismology was the development of the computer. IN addition to allowing vastly more data to be recorded, stored and processed, it enabled far more sophisticated techniques to be applied to extract information. Seismic tomography, which allows the Earth to be imaged in 2-D and 3-D, is an excellent example of the impact that the CPU had on seismology. Prior to 1970, seismic tomography in name or form simply did not exist. However, as computing power began to increase at an exponential rate, it gradually began to emerge in active source (Bois et al., 1971) and passive source imaging (Aki et al., 1977; Dziewonski et al., 1977) involving datasets of significant size. In subsequent years, the volume of data used and the sophistication of the forward and inverse solvers applied have kept pace with the growth in computing power. Today, full wave-form inversion, involving numerical solution of the elastic wave equation and large numbers of unknowns (10s-100s of thousands or more) is gradually becoming commonplace (e.g. Fichtner et al., 2013; French, 2015).

The main goal of this article is to introduce the special issue associated with the Seismix 2016 symposium on seismic imaging of continents and their margins, which was held in Aviemore, Scotland, from May 15-20 2016. However, it is also an opportunity to briefly discuss some of the latest devel- 
opments in the field which were considered at various points throughout the five day symposium. This includes (i) joint inversion of multiple datasets, which may involve purely seismic datasets such as body and surface wave, or a mix of geophysical datasets including seismic gravity, heat flow etc.; (ii) seismic interferometry, which is relevant to both diffuse and deterministic sources, and can be used for imaging purposes; and (iii) acquisition, where improved recording systems can yield far more and higher quality data than before. Some of the latest developments in these three areas are discussed below, after which a brief description of the symposium is given, and the papers contained in this special issue are introduced.

\section{Joint inversion of multiple datasets}

In seismic imaging that requires the solution of an inverse problem, it is most common to invert a single data type for a set of directly related unknowns. A classic example in seismic tomography is the inversion of traveltimes for velocity or slowness structure (Aki and Lee, 1976; Aki et al., 1977; Dziewonski et al., 1977; Bishop et al., 1985; Walck, 1988; Bijwaard et al., 1998; Widiyantoro et al., 2002; Burdick et al., 2014); assuming geometric ray theory, the traveltime is simply the integral of slowness along a path between source and receiver, which means that the inverse problem is straightforward to formulate. In seismic tomography, there are various types of datasets that can be considered, depending on the scale of the problem, the phase type used, and the property of the waveform that is exploited. In the case of teleseismic tomography, structure beneath an array is illuminated by distant earthquakes (Aki et al., 1977; Oncescu et al., 1984; Humphreys 
and Clayton, 1990; Steck et al., 1998; Ren and Shen, 2008; Rawlinson et al., 2014); local earthquake tomography uses data from earthquakes in the neighbourhood of an array to image crust and upper mantle structure (Aki and Lee, 1976; Eberhart-Phillips, 1990; Graeber and Asch, 1999; Schurr et al., 2006); refraction and wide-angle reflection tomography uses active source data to image continuous and discontinuous variations in seismic properties (Kanasewich and Chiu, 1985; Hole, 1992; Zelt and White, 1995; Bleibinhaus and Gebrande, 2006); regional and global tomography tend to use earthquake data to image the whole globe or a significant portion of it (Dziewonski et al., 1977; Nataf et al., 1984; Grand et al., 1997; Montelli et al., 2004; Burdick et al., 2014).

Apart from the arrival time or travel time of a particular phase, the properties of the seismic waveform that can be exploited include dispersion (for surface waves), frequency spectra or the whole waveform, and unknowns can involve one or more seismic properties, including $\mathrm{P}$-wave velocity, S-wave velocity, anisotropy and attenuation. Direct inversion for related properties including velocity or attenuation ratio (Walck, 1988), and bulk sound (Gorbatov and Kennett, 2003), are also possible. Surface wave tomography, which formerly was only carried out at regional and global scales, can now span from the metre scale to the global scale thanks to the advent of ambient noise tomography (Shapiro et al., 2005; Saygin and Kennett, 2009; Pilia et al., 2015).

The idea of jointly inverting multiple seismic datasets for one or more seismic properties has been around for a number of decades. Where such datasets "overlap" there is potential to yield more information than what 
can be obtained via separate inversions. In seismic tomography, studies have been done which jointly invert local earthquake and teleseismic data (Roecker et al., 1993; Zhao et al., 1994; Sato et al., 1996; Nunn et al., 2014; Huang et al., 2015), local earthquake and active source data (Parsons and Zoback, 1997; Wagner et al., 2007) and teleseismic and active source data (Rawlinson and Urvoy, 2006; Rawlinson et al., 2010). The joint inversion of body wave and surface wave data is also becoming common (West et al., 2004; Obrebski et al., 2011) due to the potential for improving both horizontal and vertical resolution in the upper mantle. On a global scale, joint inversion of multiple seismic datasets is becoming almost commonplace. For example Li and Romanowicz (1996); Su and Dziewonski (1997); Mégnin and Romanowicz (2000); Antolik et al. (2003); Ritsema et al. (2011) jointly invert surface and body wave data (and in the latter case normal modes) for seismic velocity structure in the mantle. Despite its much greater computational costs, full waveform tomography has also been used for the joint inversion of body and surface waves (French, 2015), which results in improved resolution of the mantle volume.

Although the focus in this section is on seismic tomography, there are other seismic imaging methods for which joint inversion is considered. For example, receiver function inversion, which exploits body wave conversions at discontinuities beneath a receiver, is sometimes combined with surface wave dispersion in order to increase the accuracy of absolute velocities (Julià et al., 2000). The non-linearity of the inverse problem and the sensitivity to choice of weighting between the surface wave dispersion and receiver function datasets is one of the main challenges of this technique (and indeed most 
joint inversion problems in geophysics). Bodin et al. (2012) implement a hierarchical Bayesian transdimensional scheme to tackle the joint inversion of surface wave dispersion and receiver functions. Apart from dealing with the non-linear nature of the inverse problem thanks to the underlying Markov chain Monte Carlo sampler, an arbitrary choice of weighting factors is no longer necessary due to the ability of the method to evaluate the noise content of each dataset.

Joint inversion of multiple seismic datasets has obvious attractions in that the observables are all sensitive to seismic properties. However, if we want to jointly invert data of different type, which are sensitive to very different properties of the medium (e.g. seismic wavespeed and electrical resistivity), then the problem becomes more challenging. In the realm of seismic tomography, joint inversion of seismic and gravity data is perhaps the most common (Lees and VanDecar, 1991; Roy et al., 2005; Maceira and Ammon, 2007) no doubt partly because direct parameter relationships (i.e. one property can be expressed as a function of another property) between density and wavespeed are relatively common in the literature (although they are often empirical and only valid in particular circumstances). If no valid direct parameter relationships exist, then other approaches are required. One of these is the so-called cross-gradient constraint, which achieves coupling between the parameter types by including a term in the objective function which favours structural similarity between models. The coupling between parameter types is looser when compared to direct parameter relationships, but fewer assumptions are made. The relative performance of these two approaches is examined by Moorkamp et al. (2010). Joint inversion of multi- 
ple datasets which employ cross-gradient constraints is particularly favoured in exploration and environmental geophysics, which often have overlapping datasets of different type For example, Gallardo and Meju (2003) jointly invert seismic traveltime data and DC resistivity, and Linde et al. (2008) jointly invert seismic traveltime and radar data from a crosshole experiment.

In global seismic tomography, there have been attempts to incorporate non-seismic data via direct inversion. For example, GyPSuM is a global 3-D model of mantle S-wavespeed, P-wavespeed and density derived from joint inversion of body wave traveltimes, global free-air gravity, dynamic topography, plate divergence and anomalous core-mantle boundary ellipticity (Simmons et al., 2010). Scaling relationships, which are essentially equivalent to the direct parameter relationships discussed above, are used to link S-wavespeed, P-wavespeed and density, and a strictly linear inversion approach is adopted, whereby a set of weighting parameters are used to balance the influence of the different datasets. In subsequent inversions, the scaling relationships are permitted to vary such that patterns of density, P-wave and S-wave velocity are not necessarily correlated.

Rather than describe the Earth in terms of seismic (e.g. wavepseed), electrical (e.g. resistivity), or some other property that is a direct function of the related observable, another approach is to parameterize the Earth in terms of its primary physical properties, namely composition, pressure and temperature. Given values for these parameters at a point in the Earth, it is then possible to make estimates of derivative properties such as seismic wavespeed. The advantage of this approach is that it has the potential to be thermodynamically and internally consistent, and does not require any 
direct or indirect coupling between sub-ordinate properties like wavespeed and density. Initial attempts at solving this problem using multiple datasets were 1-D (e.g. Khan et al., 2008) owing to the computational costs of dealing with significant non-linearity and non-uniqueness. In 3D, initial attempts (Shito et al., 2006) inverted velocity and attenuation structure obtained via tomography for temperature, major element geochemistry, water content and degree of partial melting. More recently, Afonso et al. (2013a,b, 2016) introduced a new "thermochemical tomography method" which allows for the inversion of multiple datasets ( $\mathrm{P}$ and $\mathrm{S}$ traveltimes, Rayleigh wave dispersion curves, geoid height, Bouguer gravity anomalies, gravity gradients, surface heat flow and elevation) for 3-D temperature, pressure and composition (defined by five parameters). A fully non-linear Bayesian probabilistic approach is used to solve the inverse problem. Application to data from the Colorado Plateau reveals a strong association between recent intraplate baslatic volcanism and underlying zones of high temperature and low MG\# (Afonso et al., 2016).

\section{Seismic interferometry}

Seismic interferometry, which refers to the principle of extracting a new signal from the cross-correlation of waveforms recorded by a pair of seismometers, has been a rapidly growing area of seismology for a decade and a half. Although first recognised by Claerbout (1968) in the context of synthesizing a reflection response from the autocorrelation of its transmission response in a layered medium, it wasn't until the early 21st century that it emerged as a major new field of development. In one of the pioneering pa- 
pers from the acoustics community, Lobkis and Weaver (2001) demonstrated both theoretically and experimentally via ultrasonic laboratory tests, that the Green's function of a medium can be recovered by cross-correlating the recordings made at two transducers from a diffuse field generated by a third transducer. They also found that with increased stacking and use of multiple sources, the quality of the recovery improves. Subsequent application to seismic recordings showed that this principle is transferable to the Earth's diffuse seismic wavefield, whether produced by so-called ambient noise or scattered coda waves from large earthquakes (Campillo and Paul, 2003; Shapiro and Campillo, 2004; Snieder, 2004; Wapenaar et al., 2005; Curtis et al., 2006).

From a seismic imaging perspective, the ability to recover the Green's function between two receivers, which has an equivalence to the signal that would be recorded at one receiver if the other was a "virtual" impulse source, meant that both new and legacy data recorded by passive seismic arrays could be exploited. The majority of applications exploit Rayleigh wave or Love wave signal extracted via cross-correlation because surface waves tend to be much more emergent than body waves (e.g. Kang and Shin, 2006; Saygin and Kennett, 2009; Arroucau et al., 2010; Young et al., 2011; Pilia et al., 2016). However, it has been demonstrated that with careful data processing and large and dense arrays, body waves of sufficient quality can be extracted and used for 3-D refraction tomography (e.g. Nakata et al., 2015).

The imaging of structure using diffuse natural (oceanic microseismic, atmospheric disturbances) or anthropogenic (human-induced) noise sources is often referred to as "ambient noise tomography", and has become commonplace in the published literature. One reason for its rapid adoption is that, 
apart from the processing required to produce the Green's function response from cross-correlation of data from station pairs, conventional tomography workflows can be applied. In the case of ambient noise surface wave tomography, group and phase dispersion analysis can be undertaken, and phase or group velocity maps produced. To obtain 3-D velocity models, pseudodispersion curves can be extracted from the group or phase velocity maps on a regular grid, and inverted for local 1-D structure; a composite 3-D model can than be produced from the regular 1-D samples (e.g. Young et al., 2013). For the body wave tomography example of Nakata et al. (2015) cited above, the inversion scheme of Hole (1992) was implemented. As such, new inversion methodologies are not often specifically developed for ambient noise tomography. However, one area where this may be required is in the full waveform inversion of ambient noise signal. The accuracy of the Green's function that is retrieved can be heavily influenced by attenuation and heterogeneous source distribution, resulting in amplitude and phase contamination, the appearance of spurious arrivals, and missing phases (e.g. Tsai, 2009; Halliday and Curtis, 2008; Fichtner, 2014). As such, direct inversion of the extracted Green's function may result in the introduction of spurious structure. In the case of Gao and Shen (2014), full waveform inversion is performed only after carrying out ensemble-averaging of cross-correlations and corresponding sensitivity kernels to help minimise the effects of irregular source distribution. Fichtner et al. (2017) develop a general theory for interferometry, which does not equate interferometry with Green's function retrieval, and accounts for heterogeneous source distribution, processing choices, seemingly unphysical arrivals, and the presence of earthquakes in the continuous data stream. The 
aim of this theory is to permit the full waveform inversion of waveform crosscorrelations which may or may not be true representations of the interstation Green's function.

Other than seismic tomography, seismic interferometry has also been exploited for more direct imaging methods, including those that attempt to migrate the entire wavefield such as seismic reflection imaging. From an exploration point of view, the use of diffuse noise sources is potentially attractive, as it may be viable as a low cost and environmentally friendly alternative to active source imaging, which usually require explosives, air-guns or vibroseis trucks. However, there are major challenges to be overcome, including the low amplitude of body waves in cross-correlations and the often limited high frequency content of noise sources. However, developments in this field are rapid, and usable results have been obtained (Dragonov et al., 2009; Nakata et al., 2011; Quiros et al., 2016). Interferometric seismic imaging in exploration is not limited to exploiting only diffuse sources of energy. For example, it can be used with conventional reflection seismic data to improve migration imaging (Schuster et al., 2004). A natural extension to this kind of interferometric imaging is so-called Marchenko imaging (Wapenaar et al., 2014), which, using only sources and receivers located at the surface, is able to retrieve the Green's function for a subsurface source. Conventional interferometry requires a receiver to be located at the virtual source. Application of Marchenko imaging to reflection data allows the extraction of a reflection response which suppresses spurious arrivals related to a complex overburden (Wapenaar et al., 2014; Sing et al., 2014).

In passive seismic imaging, autocorrelation of the diffuse wavefield or 
teleseismic coda waves is starting to become more popular as a direct imaging tool. Compared to standard cross-correlation of waveforms at separate stations, autocorrelation of waveforms at a single station has the advantage that the surface wave component is effectively removed (Gorbatov et al., 2013), and the remaining response can be related to the reflectivity structure beneath the station. Although the majority of studies published so far have attempted to exploit the ambient noise field (Ito et al., 2012; Kennett et al., 2015; Oren and Nowack, 2017; Saygin et al., 2017), a recent study has attempted to tackle the problem using teleseismic coda waves (Phạm and Tkalčić, 2017).

Finally, seismic interferometry has also been applied to the problem of monitoring temporal changes in the subsurface, which can be of use in natural hazard or buried waste storage monitoring. Snieder et al. (2002) introduce a method for measuring small perturbations in a medium by cross-correlating coda waves from deterministic sources before and after the perturbation. Using a laboratory experiment in which a granite sample is gradually heated from $20^{\circ} \mathrm{C}$ to $90^{\circ} \mathrm{C}$, with piezo-electric transducers providing both elastic wave excitation and recording, they demonstrate that coda wave interferometry is able to detect velocity changes (which are of the order of $0.1 \%$ with $0.02 \%$ error) associated with temperature changes of $5^{\circ} \mathrm{C}$. Ambient noise recordings have also been found to be useful for monitoring changes in rock properties. For example, Wegler and Sens-Schönfelder (2007) use autocorrelations of ambient noise at a single receiver to detect a $-0.6 \%$ decrease in seismic velocity associated with a $\mathrm{Mw} 6.6$ earthquake. Brenguier et al. (2008) use 18 months of ambient seismic noise data recorded at the Piton de 
la Fournalse volcano to demonstrate that velocity perturbations of the order of $0.05 \%$ can be detected using interferometry, with a clear link between small velocity changes and pre-eruptive behaviour. Effective time-lapse monitoring over periods of years has also been shown to be possible with seismic interferometry. For example, de Ridder et al. (2014) demonstrate that variations in Scholte wave group velocity images derived from ambient noise recordings from an ocean bottom cable array over a period of 6 years are statistically significant.

\section{Acquisition}

As mentioned in the Introduction, modern seismology really only came into being in the late 19th century when instruments capable of measuring ground motion were developed. Of all the progenitors of modern seismometers, the 1895 horizontal pendulum design of John Milne, Alfred Ewing and Thomas Gray is noteworthy because it enabled teleseismic earthquakes to be recorded (Musson, 2013). These early instruments used a rotating drum with a needle on smoked paper to trace out the waveform, although these were eventually superseded by light beams and photographic paper. The WoodAnderson (WA) torsion seismograph (Anderson and Wood, 1925) did not use a pendulum; instead a small copper cylinder was attached to a tungsten wire under tension, and moved in response to ground motion. Damping was achieved by suspending the copper cylinder in a magnetic field and recordings were made by bouncing light from a mirror mounted on the mass onto photosensitive paper (Sandron et al., 2015). Most famously, the Wood-Anderson seismometer was used by Richter (1935) to define the local magnitude of 
an earthquake. More recent seismometers generally involve movement of a mass through a magnetic field, which induces a voltage which can be linked to ground motion. Modern broadband instruments employ force feedback in order to stabilise the mass and ultimately improve the accuracy of the recorded signal, particularly at long periods (Stein and Wysession, 2003).

The idea for a global network of seismic stations to detect earthquakes was first mooted in the 19th century by pioneers of the science including Mallot and Milne (Musson, 2013), and indeed by the early 20th century seismometers could be found on many continents. However, a truly global network that used standardised instrumentation with accurate timing and an established data exchange procedure did not eventuate until the 1960s with the deployment of the World-Wide Standardised Seismograph Network (WWSSN). A total of 127 stations were deployed throughout the world, although by 1978, only 115 were active (Peterson and Hutt, 2014). A photographic recording system was used, in which light was focused on a rotating drum wrapped in photographic paper; these records were changed on a daily basis (Peterson and Hutt, 2014). The WWSSN was eventually superseded by the Global Seismic Network (GSN), which was established in 1986 by the US Geological Survey, National Science Foundation and IRIS (Incorporated Research Institutions for Seismology). It now consists of more than 150 permanent broadband seismometers coupled to digital recorders and features real-time transmission of the recorded signal to the IRIS DMC, which makes all data freely available on the internet. More broadly, the FDSN (Federation of Digital Seismograph Networks) includes networks from many different countries that record high fidelity digital seismic data. Data from these stations (many 
thousand) are also archived by the IRIS DMC.

In terms of global seismology, the GSN already offers a potent tool for earthquake research and Earth imaging, which in many areas of the Earth can be supplemented by national networks. Temporary seismic arrays, which use portable instruments installed for a limited period of time are also valuable for Earthquake analysis and Earth imaging, and data from such experiments are often made available to the global community via the IRIS DMC. Many such temporary arrays are part of short projects, but in recent decades there has been a push for large programs which try to cover significant geographic regions using a so-called transportable array. Perhaps the first example of this was the SKIPPY array in Australia (Zielhuis and van der Hilst, 1996) which used a modest array of digital broadband instruments to achieve coverage of the Australian continent at approximately $400 \mathrm{~km}$ separation. This was followed by the WOMBAT array in Eastern Australia, which began in 1998, and to date has resulted in the installation of over 700 instruments as part of 17 array movements (Graeber et al., 2002; Rawlinson et al., 2006, 2014).

The largest transportable array experiment to date is USArray, which utilises 400 high quality 3-component seismic instruments in order to achieve complete coverage of the United States at a station spacing of $70 \mathrm{~km}$. The experiment began in 2007, with an array deployment inboard of the west coast, which has been gradually migrated to the east in order to achieve total coverage. The bulk of the deployment is now complete, with remnants of the array now in Alaska. All data is freely available on the IRIS DMC, making it one of the largest repositories from a single experiment. To date, a vast number of studies have been carried out which make use of this data, 
largely in the context of understanding the structure and dynamics of continental lithosphere (e.g. Burdick et al., 2008; Liu et al., 2012; Buehler, 2017). Although not strictly a transportable array in the mold of USArray, WOMBAT or SKIPPY, the European AlpArray initiative aims to densely cover the Alps with approximately 260 broadband stations, which complement a preexisting network of permanent stations. To date approximately 45 institutes from 18 countries are involved in the project.

Another recent development in the field of passive seismic acquisition involves the deployment of very dense arrays in order to record more of the seismic wavefield. As technology improves, it is becoming more feasible to build cheap, highly portable and good quality instruments that can be rapidly deployed. For example, Davenport et al. (2014) deploy an array of 201 short-period vertical component seismometers for an aftershock study, which enabled very small earthquakes to be detected and highly accurate hypocenter determination. In the study of Nakata et al. (2015) mentioned previously, ambient noise body waves are extracted from a large 2-D array consisting of 2500 receivers at $100 \mathrm{~m}$ spacing. These so-called "large N" arrays are becoming increasingly popular, and tend to make use of compact systems that include a geophone, digitizer, battery, data storage and GPS in single unit that can be rapidly deployed (Brenguier et al., 2015).

In active source seismic imaging, the use of very large arrays of receivers has been around for a long time. For example, in 3-D marine seismic reflection surveys, multiple lines of receivers are towed in parallel. In the ultrahigh resolution 3D survey in the Gulf of Mexico described by Brookshire et al. (2015), $18100 \mathrm{~m}$ long streamers were towed. Each streamer contained 
receiver groups spaced at $6.25 \mathrm{~m}$, with each receiver group consisting of 12 hydrophones. Thus this "transportable" array consisted of 3456 sensors and 288 channels, and with shots fired every $12.5 \mathrm{~m}$, the volume of data recorded was immense. Large underwater arrays of ocean bottom seismic nodes, which can be used for both active and passive imaging/monitoring is another area of development (Beaudoin and Ross, 2007). Although the idea of deploying cables on the seabed populated with hydrophones has been around for several decades, the introduction of cheap, portable, self-contained and autonomous recording devices which can be readily deployed in their thousands has had a major influence on the acquisition of marine reflection data (Bunting and Moses, 2016).

The rapid increase in the size of recorded seismic datasets, both in exploration and solid earth applications is only set to continue. In part,this is due to developments in sensor technology, which allows for cheaper and much more portable recording units to be developed. For example, fibre-optic sensors are cost-effective, allow for very dense sampling, and have recently been developed for both land and marine use (Molteni et al., 2016). Continuous optical fibre sensors fall under the category of distributed acoustic sensing (DAS), a rapidly developing field which has revolutionized borehole seismic and is in the process of migrating to other areas of seismic acquisition (Mateeva et al., 2013). 


\section{The symposium: deep seismic imaging of continents and their margins}

"Seismix" is an international symposium on seismic imaging that is held every two years. The first meeting was held at Cornell in 1984 and the series has gone on to establish a truly international profile thanks to subsequent hostings in various parts of the world, including New Zealand, Canada, China, Spain, Australia and Finland. The original motivation for the conference series was the emergence of coordinated national efforts to apply multi-channel seismic reflection profiling methods to understand the structure of continents and their margins. Notable examples include BELCORP in Belgium, Lithoprobe in Canada, Fire in Finland, DEKORP in Germany, ESCI in Spain and BIRPS in the UK. However, since the main goal of the symposium is to apply cutting edge methods to understand structure and processes in the crust and mantle lithosphere beneath continents, there has by necessity been a diversification in the data used and methods applied. Most notably, passive seismic imaging methods have become an integral part of the symposium, with receiver function studies, ambient noise imaging and earthquake tomography now presented alongside deep reflection profiling.

Seismix 2016 was held in Aviemore, Scotland between May 15-20, 2016, and represents the 17th gathering of the Seismix community. It was primarily organised by the University of Aberdeen, but received assistance from Imperial College London and the British Geological Survey. The program committee comprised 16 individuals from 14 research institutions around the UK. A total of 150 researchers from the UK and around the world attended the symposium, which included four and a half days of talks and posters and 
a half day field trip. The sessions were divided into the following subject areas:

- Novel seismic imaging using interferometry

- Joint inversion of multiple datasets

- Advanced seismic imaging and inversion methods

- Innovative seismic acquisition a nd processing techniques

- Real time monitoring and subsurface imaging

- Shallow subsurface imaging

- Seismic imaging of sedimentary basins

- Continental margins and sedimentary basins

- Oceanic lithosphere and mantle

- The North Atlantic lithosphere and mantle

- Continental lithosphere

- Lithospheric subduction

- Back-arc lithosphere

- Orogenic lithosphere

- Magmatism and hydrothermal processes in the lithosphere 
During the symposium, there were 81 oral presentations and 89 poster presentations. The underlying theme of the conference was "seismology at the cross-roads", because as the above session list attests, Seismix has the unique ability to bring together those from the active and passive source imaging community, as well as those who study the Earth from the exploration to the continental scale.

One tradition of the Seismix symposia is to publish a special issue which features some of the latest research from conference attendees. Table 1 provides a list of all the previous special issues from Seismix, dating back to 1984. Below, a brief summary of each contribution to the Seismix 2016 special issue is provided. While these papers by no means span all the subject areas that were covered during the course of the symposium, they do reflect the diversity of presentations that make Seismix such an exciting biennial event.

\section{In this volume}

The following papers are based on presentations given at Seismix 2016:

Aarseth et al. [this volume] use seismic data from an OBS profile across the western Barents Sea to map crust and upper mantle structure in order to discriminate between different Caledonian structural trends and rift basin orientations. Refraction and wide-angle reflection P-wave traveltimes are inverted for layered crustal velocity structure, and constraints from gravity modelling are also considered. Their findings support the existence of Barentsia as an independent microcontinent between Baltica and Laurentia. Calvert [this volume] presents a method analogous to semblance veloc- 
ity analysis for estimating 3-D reflector orientations along 2-D deep seismic reflection profiles. The method is tested on data from the Yilgarn craton in Australia, and is found to work except for near linear seismic lines. The results suggest that the placement of additional receivers, possibly as crossrecording spreads, will be sufficient to supplement the limited range of azimuths from in-line acquisitions.

He et al. [this volume] exploit teleseismic pmP reflections from the Moho underside to examine crustal thickness variations beneath the intermediate seismic zone of the Pamir-Hindu Kush region. The deepest interface is found to be nearly $97 \mathrm{~km}$ below the southernmost Pamir, which points to the presence of subducted Asian lower crust in the study area.

Lee et al. [this volume] examine the stress field in the continental margin region of the Korean Peninsula and Japanese Islands using earthquake focal mechanisms. They find that the crustal stress fields in the neighbourhood of subduction zones adjacent to the Japanese islands exhibit depth-dependent orientations. They also find that the regional stress field, which was perturbed by the magnitude 9 Tohoku earthquake in 2011, recovered to its normal state in a few years.

Ishiyama et al. [this volume] image active blind faults in Japan using highresolution 2D seismic reflection profiling. Data is sourced from an 8-km long seismic line which crosses compressionally reactivated normal faults within a back-arc failed rift along the southwestern extension of the Toyoma trough in the Sea of Japan. The new images illuminate previously unrecognised thrustrelated structures beneath the on-shore alluvial plain, and demonstrate the usefulness of high resolution profiling in delineating active faults in regions 
where basement is buried by sedimentary cover.

Krzywiec et al. [this volume] use seismic reflection data to investigate sedimentary cover on the SW slope of the East European Craton in Poland. They demonstrate that following improved data processing techniques, the structural patterns revealed by the POLCRUST-01 profile may be explained by thin-skinned tectonics; this is in contrast to previous studies which also found evidence for thick-skinned tectonics. They also find evidence to suggest that most of the south-westward tilt of the cratonic basement is preOrdovician in age.

Roots et al. [this volume] carry out interferometric seismic imaging around the Lalor mine in the Flin Flon greenstone belt, Canada. Here, data from a dense array of 336 receivers, each recording 300 hours of ambient seismic noise, were used to generate virtual shot gathers along three receiver lines. Coherent events in the passive reflection profiles can be associated with geological contacts, which bodes well for future developments of this technique.

Song et al. [this volume] image the Moho beneath south China using teleseismic wavefield construction based on the radial basis function (RBF) technique. They demonstrate that compared to the stacking, the RBF technique exhibits more detail and produces depths which appear to be more consistent with changes in tectonic province.

Syracruse et al. [this volume] present a new method for the joint inversion of body wave, surface wave dispersion and gravity data for 3D P-and S-wave velocity structure. The method is tested on USArray data from Utah to image the crust and upper mantle structure. Results show clear delin- 
eations between the three primary tectonic provinces, with synthetic testing demonstrating that the combined dataset dramatically improves the recovery of S-wave velocities, whereas the improvements to $\mathrm{P}$-wave structure is more subtle.

Yelisetti et al. [this volume] migrate seismic reflection data recorded by widely-spaced OBSs in order to image structure beneath the northern Cascadia margin. They employ a mirror-imaging or multiple-migration technique, which is shown to be superior even to coincident multichannel reflection imaging. The resultant images reveal for the first time a dual-vergent structure, which may be a consequence of horizontal compression caused by subduction and low basal shear stress caused by over-pressure.

\section{Acknowledgements}

The 17th International Symposium on seismic imaging of the continents and their margins (Seismix 2016) was organised by the University of Aberdeen, with organising committee members also drawn from Imperial College London and the British Geological Survey. The Program Committee was drawn from academia, government and industry from around the UK, and are acknowledged for their efforts in putting together a cohesive and exciting set of talks and posters. Financial sponsorship from the British Geophysical Association, Tectonic Studies Group of the Geological Society of London, International Lithosphere Program, Güralp, European Geosciences Union, Ion and Nanometrics is gratefully acknowledged. 


\section{References}

Afonso, J. C., Fullea, J., Griffin, W. L., Yang, Y., Jones, A. G., Connolly, J. A. D., O'Reilly, S. Y., 2013a. 3D multi-observable probabilistic inversion for the compositional and thermal structure of the lithosphere and upper mantle. I: a priori petrological information and geophysical observables. J. Geophys. Res. 118, 2586-2617.

Afonso, J. C., Fullea, J., Yang, Y., Connolly, J. A. D., Jones, A. G., 2013b. 3D multi-observable probabilistic inversion for the compositional and thermal structure of the lithosphere and upper mantle. II: General methodology and resolution analysis. J. Geophys. Res. 118, 1650-1676.

Afonso, J. C., Rawlinson, N., Yang, Y., Schutt, D. L., Jones, A. G., Fullea, J., Griffin, W. L., 2016. 3-D multiobservable probabilistic inversion for the compositional and thermal structure of the lithosphere and upper mantle: III. Thermochemical tomography in the Western-Central U.S. J. Geophys. Res. 121, 7337-7370.

Aki, K., Christoffersson, A., Husebye, E. S., 1977. Determination of the three-dimensional seismic structure of the lithosphere. J. Geophys. Res. $82,277-296$.

Aki, K., Lee, W. H. K., 1976. Determination of the three-dimensional velocity anomalies under a seismic arraynusing first $P$ arrival times from local earthquakes 1. A homogeneous intial model. J. Geophys. Res. 81, 4381-4399. 
Anderson, J. A., Wood, H. O., 1925. Description and theory of the torsion seismometer. Bull. Seism. Soc. Am. 15, 1-72.

Antolik, M., Gu, Y. J., Ekstrom, G., Dziewonski, A. M., 2003. A new joint model of compressional and shear velocity in the Earth's mantle. Geophys. J. Int. 153, 443-466.

Arroucau, P., Rawlinson, N., Sambridge, M., 2010. New insight into Cainozoic sedimentary basins and Palaeozoic suture zones in southeast Australia from ambient noise surface wave tomography. Geophys. Res. Lett. 37, L07303, doi:10.1029/2009GL041974.

Barazangi, M., Brown, L., 1986. Reflection Seismology: A Global Perspective. Am. Geophys. Union, Geodyn. Ser., 13. 311pp.

Beaudoin, G., Ross, A. A., 2007. Field design and operation of a novel deepwater, wide-azimuth node seismic survey. The Leading Edge 26, 494-503.

Ben-Menahem, A., 1995. A concise history of mainstream seismology: Origins, legacy and perspectives. Bull. Seism. Soc. Am. 85, 1202-1225.

Bijwaard, H., Spakman, W., Engdahl, E. R., 1998. Closing the gap between regional and global travel time tomography. J. Geophys. Res. 103, 30,05530,078 .

Bishop, T. P., Bube, K. P., Cutler, R. T., Langan, R. T., Love, P. L., Resnick, J. R., Shuey, R. T., Spindler, D. A., Wyld, H. W., 1985. Tomographic determination of velocity and depth in laterally varying media. Geophysics 50, 903-923. 
Bleibinhaus, F., Gebrande, H., 2006. Crustal structure of the Eastern Alps along the TRANSALP profile from wide-angle seismic tomography. Tectonophysics 414, 51-69.

Bodin, T., Sambridge, M., Tkalcic, H., Arroucau, P., Gallagher, K., Rawlinson, N., 2012. Transdimensional inversion of receiver functions and surface wave dispersion. J. Geophys. Res. 117, B02301, doi:10.1029/2011JB008560.

Bois, P., La Porte, M., Lavergne, M., Thomas, G., 1971. Essai de détermination automatique des vitesses sismiques par mesures entre puits. Geophysical Prospecting 19, 42-83.

Brenguier, F., Kowalski, P., Ackerley, N., Nakata, N., Boué, P., Campillo, M., Larose, E., Rambaud, S., Pequegnat, C., Lecoq, T., Roux, P., Ferrazzini, V., Villeneuve, N., Shaprio, N. M., Chaput, J., 2015. Toward 4D NoiseBased Seismic Probing of Volcanoes: Perspectives from a LargeN Experiment on Piton de la Fournaise Volcano. Seismol. Res. Lett. 87, 15-25.

Brenguier, F., Shapiro, N. M., Campillo, M., Ferrazzini, V., Dupute, Z., Coutant, O., Nercessian, A., 2008. Towards forecasting volcanic eruptions using seismic noise. Nature Geosciences 1, 126-130.

Brookshire, B. N., Landers, F. P., Stein, J. A., 2015. Applicability of ultrahigh-resolution 3D seismic data for geohazard identification at mid-slope depths in the Gulf of Mexico: Initial results. Underwater Technology 32, $271-278$.

Buehler, J. S., 2017. Uppermost mantle seismic velocity structure beneath usarray. J. Geophys. Res. 122, 436-448. 
Bunting, T., Moses, J., 2016. The transformation of seabed seismic. First Break 34, 59-64.

Burdick, S., Li, C., Martynov, V., Cox, T., Eakins, J., Astiz, L., Vernon, F. L., Pavlis, G. L., Van der Hilst, R. D., 2008. Upper mantle heterogeneity beneath North America from travel time tomography with global and USArray transportable array data. Seismol. Res. Lett. 79, 384-392.

Burdick, S., Van der Hilst, R. D., Vernon, F. L., Martynov, V., Cox, T., Eakins, J., Karasu, G. H., Tylell, J., Astiz, L., Pavlis, G. L., 2014. Model Update January 2013: Upper mantle heterogeneity beneath North America from travel time tomography with global and USArray transportable array data. Seismol. Res. Lett. 85, 77-81.

Campillo, M., Paul, A., 2003. Long-range correlations in the diffuse seismic coda. Science 299, 547-549.

Carbonell, R., Gallart, J., Torne, M., 2000. Deep seismic profiling of the continents and their margins selected papers from the 8th International Symposium on Deep Seismic Profiling of the Continents and their Margins, Barcelona, Spain, 2025 September 1998 preface. Tectonophysics 329, 1-4.

Carbonell, R., Sallares, V., Ranero, C. R., Booth-Rea, G., 2016. Preface to the "Deep Seismix-2014" special issue. Tectonophysics 689, 1-3.

Claerbout, J. F., 1968. Synthesis of a layered medium from its acoustic transmission response. Geophysics 33, 264-269.

Clowes, R. M., Green, A. G., 1994. Seismic reflection probing of the continents and their margins. Tectonophysics 232, VII-IX. 
Curtis, A., Gerstoft, P., Sato, H., Snieder, R., Wapenaar, K., 2006. Seismic interferometry - turning signal into noise,. The Leading Edge 25, 1082 1092.

Davenport, K. K., Hole, J. A., Quiros, D. A., Brown, L. D., Chapman, M. C., Han, L., Mooney, W. D., 2014. Aftershock imaging using a dense seismometer array (AIDA) after the 2011 Mineral, Virginia, earthquake. GSA Special Papers 509, 273-283.

Davey, F. J., Jones, L., 2004. Special issue continental lithosphere papers presented at the 10th international symposium on deep seismic profiling of the continents and their margins taupo, new zealand, 610 january 2003 introduction. Tectonophysics 388, 1-5.

de Ridder, S. A. L., Biondi, B. L., Clapp, R. G., 2014. Time-lapse seismic noise correlation tomography at Valhall. Geophys. Res. Lett. 41, 61166122.

Dewey, J., Byerly, P., 1969. The early hisotry of seismometry (to 1900). Bull. Seism. Soc. Am. 59, 183-227.

Dragonov, D., Campman, X., Thorbecke, J., Verdel, A.and Wapenaar, K., 2009. Reflection images from ambient seismic noise. Geophysics 74, 63-67.

Dziewonski, A. M., Hager, B. H., O'Connell, R. J., 1977. Large-scale heterogeneities in the lower mantle. J. Geophys. Res. 82, 239-255.

Eberhart-Phillips, D., 1990. Three-dimensional $P$ and $S$ velocity structure in the Coalinga Region, California. J. Geophys. Res. 95, 15,343-15,363. 
Fichtner, A., 2014. Source and processing effects on noise correlations. Geophys. J. Int. 197, 1527-1531.

Fichtner, A., Stehly, L., Ermert, L., Boehm, C., 2017. Generalized interferometry I: theory for interstation correlations . Geophys. J. Int. 208, 603-638.

Fichtner, A., Trampert, J., Cupillard, P., Saygin, E., Taymaz, T., Capdeville, Y., Villasenor, A., 2013. Multi-scale full waveform inversion. Geophys. J. Int. in press, doi: 10.1093/gji/ggt118.

French, S. W.and Romanowicz, B., 2015. Broad plumes rooted at the base of the Earth's mantle beneath major hotspots. Nature 525, 95-99.

Gallardo, L. A., Meju, M. A., 2003. Characterization of heterogeneous nearsurface materials by joint 2D inversion of dc resistivity and seismic data. Geophys. Res. Lett. 30, 1658.

Gao, H., Shen, Y., 2014. Upper mantle structure of the Cascades from fullwave ambient noise tomography: Evidence for 3D mantle upwelling in the back-arc. Earth Planet. Sci. Lett. 390, 222-233.

Gorbatov, A., Kennett, B. L. N., 2003. Joint bulk-sound and shear tomography for Western Pacific subduction zones. Earth Planet. Sci. Lett. 210, $527-543$.

Gorbatov, A., Saygin, E., Kennett, B. L. N., 2013. Crustal properties from seismic station autocorrelograms. Geophys. J. Int. 192, 861-870. 
Graeber, F. M., Asch, G., 1999. Three-dimensional models of $P$ wave velocity and $P$-to- $S$ velocity ratio in the southern central Andes by simultaneous inversion of local earthquake data. J. Geophys. Res. 104, 20,237-20,256.

Graeber, F. M., Houseman, G. A., Greenhalgh, S. A., 2002. Regional teleseismic tomography of the western Lachlan Orogen and the Newer Volcanic Province, southeast Australia. Geophys. J. Int. 149, 249-266.

Grand, S. P., van der Hilst, R. D., Widiyantoro, S., 1997. Global seismic tomography: A snapshot of convection in the Earth. GSA Today 7, 1-7.

Halliday, D., Curtis, A., 2008. Seismic interferometry, surface waves and source distribution. Geophys. J. Int. 175, 1067-1087.

Hole, J. A., 1992. Nonlinear high-resolution three-dimensional travel-time tomography. J. Geophys. Res. 97, 6553-6562.

Huang, H.-H., Lin, F.-C., Schmandt, B., Farrell, J., Smith, R. B., Tsai, V. C., 2015. The Yellowstone magmatic system from the mantle plume to the upper crust. Science 348, 773-776.

Humphreys, E. D., Clayton, R. W., 1990. Tomographic image of the Southern California Mantle. J. Geophys. Res. 95, 19,725-19,746.

Ito, T., Iwasaki, T., Thybo, H., 2009. Deep seismic profiling of the continents and their margins preface. Tectonophysics 472, 1-5.

Ito, T., Shiomi, K., Nakajima, J., Hino, R., 2012. Autocorrelation analysis of ambient noise in northeastern Japan subduction zone. Tectonophysics $572,38-46$. 
Julià, J., Ammon, C. J., Hermann, R. N., Correig, A. M., 2000. Joint inversion of receiver function and surface wave dispersion observations. Geophys. J. Int. 143, 99-112.

Kanasewich, E. R., Chiu, S. K. L., 1985. Least-squares inversion of spatial seismic refraction data. Bull. Seism. Soc. Am. 75, 865-880.

Kang, T.-S., Shin, J. S., 2006. Surface-wave tomography from ambient seismic noise of accelerograph networks in southern Korea. Geophys. Res. Lett. 33, doi:10.1029/2006GL027044.

Kennett, B. L. N., Saygin, E., Salmon, M., 2015. Stacking autocorrelograms to map Moho depth with high spatial resolution in southeastern Australia. Geophys. Res. Lett. 42, 7490-7497.

Khan, A., Connolly, J. A. D., Taylor, S. R., 2008. Inversion of seismic and geodetic data for the major element chemistry and temperature of the Earth's mantle. J. Geophys. Res. 113, doi:10.1029/2007JB005239,.

Klemperer, S. L., Mooney, W. D., 1998. Special Issue Deep Seismic Profiling of the Continents, I: General Results and New Methods. Tectonophysics 286, IX-XIV.

Lees, J. M., VanDecar, J. C., 1991. Seismic tomography constrained by Bouguer gravity anomalies: Applications in western Washington. Pageoph $135,31-52$.

Leven, J. H., Finlaysson, D. M., Wright, C., Dooley, J. C., Kennett, B. L. N., 1990. Seismic probing of continents and their margins. Tectonophysics 173, 641pp. 
Li, X. D., Romanowicz, B., 1996. Global mantle shear velocity model developed using nonlinear asymptotic coupling theory. J. Geophys. Res. 101, $22,245-22,272$.

Linde, N., Tryggvason, A., Peterson, J. E., Hubbard, S. S., 2008. Joint inversion of crosshole radar and seismic traveltimes acquired at the South Oyster Bacterial Transport Site. Geophysics 73, 29-37.

Liu, K., Levander, A., Zhai, Y., Porritt, R. W., Allen, R. M., 2012. Asthenospheric flow and lithospheric evolution near the Mendocino Triple Junction. Earth Planet. Sci. Lett. 323, 60-71.

Lobkis, O. I., Weaver, R. L., 2001. On the emergence of the Green's function in the correlations of a diffuse field. J. Acoust. Soc. Am. 110, 3011-3017.

Maceira, M., Ammon, C. J., 2007. Joint inversion of surface wave velocity and gravity observations and its application to central Asian basins shear velocity structure. J. Geophys. Res. 114, B02314.

Mateeva, A., Lopez, J., Mestayer, J., Wills, P., Cox, B., Kyashchenko, D., Yang, Z., Berlang, W., Detomo, R., Grandi, S., 2013. Distributed acoustic sensing for reservoir monitoring with VSP. The Leading Edge 32, 12781283.

Matthews, D. H., Smith, C., 1987. Deep Seismic Reflection Profiling of the Continental Lithosphere. Geophys. J. Royal Astr. Soc. 89, 447pp.

Mégnin, C., Romanowicz, B., 2000. The three-dimensional shear velocity structure of the mantle from the inversion of body, surface and highermode waveforms. Geophys. J. Int. 143, 709-728. 
Meissner, R., 1991. Continental Lithosphere: Deep Seismic Reflections. Am. Geophys. Union, Geodyn. Ser., 22. 450pp.

Molteni, D., Hopperstad, J.-F., Hartog, A., 2016. Use of distributed fibreoptic sensing for marine seismic measurements. First Break 34, 53-60.

Montelli, R., Nolet, G., Dahlen, F. A., Masters, G., Engdahl, E. R., Hung, S.-H., 2004. Finite-frequency tomography reveals a variety of plumes in the mantle. Science 303, 338-343.

Moorkamp, M., Heincke, B., Jegen, M., Roberts, A. W., Hobbs, R. W., 2010. A framework for 3-D joint inversion of MT, gravity and seismic refraction data. Geophys. J. Int. 184, 477-493.

Musson, R. M. W., 2013. A history of British Seismology. Bulletin of Earthquake Engineering 11, 715-861.

Nakata, N., Chang, J., Lawrence, J. F., Boué, P., 2015. Body wave extraction and tomography at Long Beach, California, with ambient-noise interferometry. J. Geophys. Res. 120, 1159-1173.

Nakata, N., Snieder, R., Larner, K., Tsuji, T., Matsuoka, T., 2011. Shearwave imaging from traffic noise using seismic interferometry by crosscoherence. SEG Expanded Abstracts 30, doi:10.1190/1.3627505.

Nataf, H.-C., Nakanishi, I., Anderson, D. L., 1984. Anisotropy and shearvelocity heterogeneities in the upper mantle. Geophys. Res. Lett. 11, 109112. 
Needham, J., 1959. Science and Civilisation in China: Volume 3, Mathematics and the Sciences of the Heavens and the Earth. Cambridge University Press, Cambridge.

Nunn, C., Roecker, S. W., Priestley, K. F., Liang, X., Gilligan, A., 2014. Joint inversion of surface waves and teleseismic body waves across the Tibetan collision zone: the fate of subducted Indian lithosphere. Geophysical Journal International 198, 1526-1542.

Obrebski, M., Allen, R. M., Pollitz, F., Hung, S.-H., 2011. Lithosphereasthenosphere interaction beneath the western United States from the joint inversion of body-wave traveltimes and surface-wave phase velocities. Geophys. J. Int. 185, 1003-1021.

Oncescu, M. C., Burlacu, V., Anghel, M., Smalbergher, V., 1984. Threedimensional $P$-wave velocity image under the Carpathian Arc. Tectonophysics 106, 305-319.

Oren, C., Nowack, R. L., 2017. Seismic body-wave interferometry using noise auto-correlations for crustal structure. Geophys. J. Int. 208, 321-332.

Parsons, T., Zoback, M. L., 1997. Three-dimensional upper crustal velocity structure beneath San Francisco Peninsula, California. J. Geophys. Res. $102,5473-5490$.

Peterson, J., Hutt, C. R., 2014. World-Wide Standardized Seismograph Network: A Data Users Guide. Open-file report 2014-1218, United States Geological Survey. 
Phąm, T.-S., Tkalčić, H., 2017. On the feasibility and use of teleseismic P wave coda autocorrelation for mapping shallow seismic discontinuities. J. Geophys. Res. 122, 3776-3791.

Pilia, S., Arroucau, P., Rawlinson, N., Reading, A. M., Cayley, R. A., 2016. Inherited crustal deformation along the East Gondwana margin revealed by seismic anisotropy tomography. Geophys. Res. Lett. 43, 12082-12090.

Pilia, S., Rawlinson, N., Cayley, R. A., Musgrave, R., Reading, A. M., Direen, N. G., Young, M. K., 2015. Evidence of micro-continent entrainment during crustal accretion. Scientific Reports 5, doi:10.1038/srep/08218.

Quiros, D. A., Brown, L. D., Kim, D., 2016. Seismic interferometry of railroad induced ground motions: body and surface wave imaging. Geophys. J. Int. 205, 301-313.

Rawlinson, N., Goleby, B. R., 2012. Seismic imaging of continents and their margins: New research at the confluence of active and passive seismology. Tectonophysics 572, 1-6.

Rawlinson, N., Reading, A. M., Kennett, B. L. N., 2006. Lithospheric structure of Tasmania from a novel form of teleseismic tomography. J. Geophys. Res. 111, doi:10.1029/2005JB003803.

Rawlinson, N., Salmon, M., Kennett, B. L. N., 2014. Transportable seismic array tomography in southeast Australia: Illuminating the transition from Proterozoic to Phanerozoic lithosphere. Lithos 189, 65-76. 
Rawlinson, N., Tkalčić, H., Reading, A. M., 2010. Structure of the Tasmanian lithosphere from 3-D seismic tomography. Australian Journal of Earth Sciences 57, 381-394.

Rawlinson, N., Urvoy, M., 2006. Simultaneous inversion of active and passive source datasets for 3-D seismic structure with application to Tasmania. Geophys. Res. Lett. 33, L24313.

Ren, Y., Shen, Y., 2008. Finite frequency tomography in southeastern Tibet: Evidence for the causal relationship between mantle lithosphere delamination and the northsouth trending rifts. J. Geophys. Res. 113, B10316, doi:10.1029/2008JB005615.

Richter, C. F., 1935. An instrumental earthquake magnitude scale. Bull. Seism. Soc. Am. 25, 1-32.

Ritsema, J., Deuss, A., van Heijst, H. J., Woodhouse, J. H., 2011. S40RTS: a degree-40 shear velocity model for the mantle from new Rayleigh wave dispersion, teleseismic traveltime and normal-mode splitting function measurements. Geophys. J. Int. 184, 1223-1236.

Roecker, S., Sabitova, T. M., Vinnik, L. P., Burmakov, Y. A., Golvanov, M. I., Mamatkanova, R., Munirova, L., 1993. Three-dimensional elastic wave velocity structure of the western and central tien shan. J. Geophys. Res. 98, 15779-15795.

Roy, L., Sen, M. K., McIntosh, K., Stoffa, P. L., Nakamura, Y., 2005. Joint inversion of first arrival seismic travel-time and gravity data. J. Geophys. Eng. 2, 277-289. 
Rui, F., Yan-xiang, Y., 2006. Zhang Heng's seismometer and Longxi earthquake in AD 134. Acta Seismologica Sinica 19, 704-719.

Sandron, D., Gentile, G. F., Gentili, S., Saraò, A., REbez, A., Santulin, M., Slejko, D., 2015. The Wood-Anderson of Trieste (northeast Italy): One of the last operating torsion seismometers. Seismol. Res. Lett. 86, 1-10.

Santosh, A., Carbonell, R., Artemieva, I., Badal, J., 2014. Advances in seismic imaging of the Crust and matle: Preface. Tectonophysics 627, 1-3.

Sato, T., Kosuga, M., Tanaka, K., 1996. Tomographic inversion for $P$ wave velocity structure beneath the northeastern Japan arc using local and teleseismic data. J. Geophys. Res. 101, 17,597-17,615.

Saygin, E., Cummins, P. R., Lumley, D., 2017. Retrieval of the P wave reflectivity response from autocorrelation of seismic noise: Jakarta Basin, Indonesia. Geophys. Res. Lett. 44, 792-799.

Saygin, E., Kennett, B., 2009. Ambient seismic noise tomography of Australian continent. Tectonophysics, doi:10.1016/j.tecto.2008.11.013.

Schurr, B., Rietbrock, A., Asch, G., Kind, R., Oncken, O., 2006. Evidence for lithospheric detachment in the central Andes from local earthquake tomography. Tectonophysics 415, $203-223$.

Schuster, G. T., Yu, J., Sheng, J., Rickett, J., 2004. Interferometric/daylight seismic imaging. Geophys. J. Int. 157, 838-852.

Shapiro, N. M., Campillo, M., 2004. Emergence of broadband Rayleigh waves 
from correlations of the ambient seismic noise. Geophys. Res. Lett. 31, doi:10.1029/2004GL019491.

Shapiro, N. M., Campillo, M., Stehly, L., Ritzwoller, M. H., 2005. Highresolution surface wave tomography from ambient seismic noise. Science $307,1615-1618$.

Shito, A., Karato, S.-I., Matsukage, K. N., Nishibara, Y., 2006. Towards mapping the three-dimensional distribution of waterin the upper mantle from velocity and attenuation tomography. In: Earth's Deep Water Cycle. Vol. Geophysical Monograph Series 168. American Geophysical Union, Washington, D.C., pp. 225-236.

Simmons, N. A., Forte, A. M., Boschi, L., Grand, S. P., 2010. GyPSuM: A joint tomographic model of mantle density and seismic wave speeds. J. Geophys. Res. 115, B12310.

Sing, S., Snieder, R., Behura, J., van der Neut, J., Wapenaar, K., Slob, E., 2014. Marchenko imaging: Imaging with primaries, internal multiples, and free-surface multiples. Geophysics 80, 165-174.

Snieder, R., 2004. Extracting the Green's function from the corelation of coda waves: A derivation based on stationary phase. Physical Review E 69, DOI:10.1103/PhysRevE.69.046610.

Snieder, R., Grêt, A., Douma, H., Scales, J., 2002. Coda Wave Interferometry for Estimating Nonlinear Behavior in Seismic Velocity. Science 295, 22532255 . 
Snyder, D. B., Eaton, D. W., Hurich, C. A., 2006. Special issue seismic probing of continents and their margins introduction. Tectonophysics 420, $1-4$.

Steck, L. K., Thurber, C. H., Fehler, M., Lutter, W. J., Roberts, P. M., Baldridge, W. S., Stafford, D. G., Sessions, R., 1998. Crust and upper mantle $P$ wave velocity structure beneath Valles caldera, New Mexico: Results from the Jemez teleseismic tomography experiment. J. Geophys. Res. 103, 24,301-24,320.

Stein, S., Wysession, M., 2003. An introduction to seismology, earthquake and earth structure. Blackwell Publishing, Oxford.

Su, W.-J., Dziewonski, A. M., 1997. Simultaneous inversion for 3-D variations in shear and bulk velocity in the mantle. Phys. Earth Planet. Inter. 100, $135-156$.

Thybo, H., 2002. Deep seismic probing of the continents and their margins selected papers from the 9th biennial meeting held in Ulvik, Norway. Tectonophysics 355, 1-5.

Thybo, H., Heikkinen, P., Kukkonen, I., 2011. Deep seismic probing of continental crust and mantle. Tectonophysics 508, 1-5.

Tsai, V. C., 2009. On establishing the accuracy of noise tomography traveltime measurements in a realistic medium. Geophys. J. Int. 178, 1555-1564.

Wagner, D., Koulakov, I., Rabbel, W., Luehr, B.-G., Wittwer, A., Kopp, H., Bohm, M., Asch, G., 2007. Joint inversion of active and passive seismic data in Central Java. Geophys. J. Int. 170, 923-932. 
Walck, M. C., 1988. Three-dimensional $V_{p} / V_{s}$ variations for the Coso region, California. J. Geophys. Res. 93, 2047-2052.

Wapenaar, K., Fokkema, J., Snieder, R., 2005. Retrieving the Green's function in an open system by cross correlation: A comparison of approaches. J. Acoust. Soc. Am. 118, 2783-2786.

Wapenaar, K., Thorbecke, J., can der Neut, J., Broggini, F., Slob, E., Snieder, R., 2014. Marchenko imaging. Geophysics 79, 39-57.

Wegler, U., Sens-Schönfelder, C., 2007. Fault zone monitoring with passive image interferometry. Geophys. J. Int. 168, 1029-1033.

West, M., Gao, W., Grand, S., 2004. A simple approach to the joint inversion of seismic body and surface waves applied to the southwest U.S. Geophys. Res. Lett. 31.

White, D. J., Ansorge, J., Bodoky, T. J., Hajnal, Z., 1996. Special issue seismic reflection probing of the continents and their margins preface. Tectonophysics 264, VII-IX.

Widiyantoro, S., Gorbatov, A., Kennett, B. L. N., Fukao, Y., 2002. Improving global shear wave traveltime tomography using three- dimensional ray tracing and iterative inversion. Geophys. J. Int. 141, 747-758.

Young, M. K., Rawlinson, N., Arroucau, P., Reading, A. M., Tkalčić, H., 2011. High-frequency ambient noise tomography of southeast Australia: New constraints on Tasmania's tectonic past. Geophys. Res. Lett. 38, L13313, doi:10.1029/2011GL047971. 
${ }_{945}$ Young, M. K., Rawlinson, N., Bodin, T., 2013. Transdimensional inversion 946 of ambient seismic noise for 3D shear velocity structure of the Tasmanian ${ }_{947} \quad$ crust. Geophysics 78, doi:10.1190/geo2012-0356.1.

948

949

Zelt, C. A., White, D. J., 1995. Crustal structure and tectonics of the southeastern Canadian Cordillera. J. Geophys. Res. 100, 24,255-24,273.

Zhao, D., Hasegawa, A., Kanamori, H., 1994. Deep structure of Japan subduction zone as derived from local, regional, and teleseismic events. J. Geophys. Res. 99, 22,313-22,329.

Zielhuis, A., van der Hilst, R. D., 1996. Upper-mantle shear velocity beneath eastern Australia from inversion of waveforms from SKIPPY portable arrays. Geophys. J. Int. 127, 1-16. 
Table 1: A brief history of Seismix and its associated special issues

\begin{tabular}{ccccc}
\hline \hline Symposium \# & Year & Location & Country & Special issue \\
\hline 1 & 1984 & Cornell & USA & Barazangi and Brown (1986) \\
2 & 1986 & Cambridge & UK & Matthews and Smith (1987) \\
3 & 1988 & Canberra & Australia & Leven et al. (1990) \\
4 & 1990 & Bayereuth & Germany & Meissner (1991) \\
5 & 1992 & Banff & Canada & Clowes and Green (1994) \\
6 & 1994 & Budapest & Hungary & White et al. (1996) \\
7 & 1996 & Asilomar & USA & Klemperer and Mooney (1998) \\
8 & 1998 & Platja D'Aro & Spain & Carbonell et al. (2000) \\
9 & 2000 & Ulvik & Norway & Thybo (2002) \\
10 & 2003 & Taupo & New Zealand & Davey and Jones (2004) \\
11 & 2004 & Mont-Treblant & Canada & Snyder et al. (2006) \\
12 & 2006 & Hayama & Japan & Ito et al. (2009) \\
13 & 2008 & Saariselkä & Finland & Thybo et al. (2011) \\
14 & 2010 & Cairns & Australia & Rawlinson and Goleby (2012) \\
15 & 2012 & Beijing & China & Santosh et al. (2014) \\
16 & 2014 & Barcelona & Spain & Carbonell et al. (2016) \\
\hline
\end{tabular}

